\title{
Bead-releasing agents used in the preparation of solid samples as beads for WD-XRF measurement
}

\author{
M.F. GAZULLA, A. BARBA, M. ORDUÑA, M. RODRIGO \\ Instituto de Tecnología Cerámica. \\ Asociación de Investigación de las Industrias Cerámicas. \\ Universitat Jaume I. Castellón. Spain.
}

\begin{abstract}
A study has been undertaken of bead-releasing agents that are widely used in preparing solid samples as fused beads for wavelength-dispersive X-ray fluorescence (WD-XRF) spectrometry measurement.

The following bead-releasing agents were studied: $\mathrm{NaI}, \mathrm{LiBr}, \mathrm{NH}_{4} \mathrm{I}$, and LiI. Each was incorporated in different quantities, as a solid and/or in an aqueous solution, together with a flux, into samples of ceramic raw materials. Release agent interference in the WD-XRF measurement was analysed, and the optimum quantity of release agent needed to obtain suitable beads for WD-XRF measurement was determined.

The best results were obtained for LiI, which yielded reproducible beads without significant interference in the WD-XRF measurement when a relatively small quantity $(0.11 \mathrm{LiI}$ g/bead $)$ was used.
\end{abstract}

\section{Introduction}

The determination of the quantitative chemical composition of solid samples, using wavelength-dispersive X-ray fluorescence spectrometry (WD-XRF), requires suitable sample preparation in order to obtain accurate and reproducible measurements.

The powder samples to be measured by WD-XRF are generally prepared as pellets or fused beads [1-4], fused beads being more widely used, except in the case of metals or nonoxidised samples, such as $\mathrm{SiC}$, which cannot be fused because they attack the platinum crucibles that hold them during the fusion process, or when a volatile element is to be analysed that would be lost during fusion. 
Sample preparation in the form of beads has the advantage of suppressing the effects of particle size and mineralogical structure, and of minimising the matrix effects in the WD$\mathrm{XRF}$ measurement, which are present when the sample is prepared in the form of pellets [1].

Beads are prepared by mixing the sample with a flux and a bead-releasing agent in a platinum crucible, and subjecting the mixture to high-temperature treatment in a fusion bead machine or a muffle kiln, after which the resulting melt is cooled in a platinum-rhodium alloy mould. Pellets are prepared by mixing the sample with a binding agent, followed by pressing in a suitable die.

A number of problems can occur in bead preparation: the fused sample may adhere to the crucible, the beads may adhere to the platinum-rhodium mould in which they have been cooled and then break, etc. To avoid such problems, bead-releasing agents are used to increase the surface tension of the melt, in order to facilitate bead release from the mould and obtain suitable beads for WD-XRF measurement [5].

A literature search showed that the following additives are used as bead-releasing agents: $\mathrm{NaI}, \mathrm{LiBr}, \mathrm{NH}_{4} \mathrm{I}$, LiI, and $\mathrm{LiF}$ [5-8]. However, studies also show that the use of a release agent may interfere in the WD-XRF measurement of a fused bead sample if the release agent contains an analyte element, or if it produces matrix effects (absorption and strengthening) or line overlap [9].

Thus, when sodium iodide (NaI) is used, this produces sodium interference. Sodium cannot be analysed, therefore, in samples prepared with NaI, while interference is also caused by iodine overlap with titanium. When lithium bromide $(\mathrm{LiBr})$ is used, the bromine interferes mainly as a matrix effect in the analysis of zirconium [10], though also to a lesser extent in that of calcium, iron, and silicon, while it overlaps with aluminium [11]. Lithium fluoride (LiF) contains fluorine, which can react with the silicon contained in the samples to be analysed to form silicon tetrafluoride $\left(\mathrm{SiF}_{4}\right)$ and, since this is a volatile compound, part of the silicon may be lost in the sample preparation process. Since the samples involved in this study contained $\mathrm{Si}$, LiF was excluded from the present work. 
With regard to possible interferences caused by $\mathrm{NH}_{4} \mathrm{I}$ and $\mathrm{LiI}$, however, no studies were found in the literature on the effects of their use as bead-releasing agents, though release agents other than $\mathrm{NaI}, \mathrm{LiBr}$, and $\mathrm{LiF}$ need to be used, given the interferences that they cause. The present study examines the interferences caused by the use of $\mathrm{NH}_{4} \mathrm{I}$ and LiI, as well as those of $\mathrm{NaI}$ and $\mathrm{LiBr}$, in the WD-XRF measurement of fused bead samples of clays and zirconium silicates. Each release agent was incorporated in different quantities (as a solid and/or in a solution), together with a flux, into the samples. The minimum quantity of release agent required to obtain reproducible beads for WD-XRF measurement was determined.

\section{Experimental part}

\subsection{Experimental technique}

\subsubsection{Sample preparation}

To obtain fused beads for the study, appropriate quantities of sample and flux were mixed with a bead-releasing agent and heat treated at high temperature. The samples were prepared by weighing between 0.4 and $0.7 \mathrm{~g}$ sample into a platinum crucible, using an analytical balance with a weighing uncertainty of $0.1 \mathrm{mg}$. The flux was then added in an appropriate sample:flux ratio (1:10) for the study, in addition to the bead-releasing agent. The mixture was heat treated in a fusion bead machine with previously programmed working times and temperatures. The working conditions are presented in Table 1.

Various quantities of each release agent, incorporated as a solid and/or in an aqueous solution into the respective samples, were tested. The additions and tests conducted were as follows:

1) $\mathrm{NaI}$ was incorporated in solid form, in a quantity of $0.09 \mathrm{~g} \mathrm{NaI} / \mathrm{bead}$.

2) $\mathrm{LiBr}$ was added in an aqueous solution with a concentration of $250 \mathrm{~g} \cdot \mathrm{L}^{-1}$ [12]. Five drops of the solution $(\approx 0.25 \mathrm{~mL})$ were added to each bead, corresponding to $0.06 \mathrm{~g} \mathrm{LiBr} / \mathrm{bead}$. 
3) $\mathrm{NH}_{4} \mathrm{I}$ was added both as a solid and in an aqueous solution. Table 2 lists the quantities of $\mathrm{NH}_{4} \mathrm{I}$ used in the various tests.

4) LiI was added in an aqueous solution with a concentration of $250 \mathrm{~g} \cdot \mathrm{L}^{-1}$. The test quantities are shown in Table 3.

To establish the optimum quantities of the bead-releasing agents being studied, different quantities of each were used in bead preparation until the melt no longer adhered to the crucible or platinum mould, the beads no longer broke (owing to stresses produced during cooling), and beads were obtained that provided accurate and reproducible WD-XRF measurement results.

\subsubsection{Sample measurement}

In order to determine whether bead preparation had been appropriate, WD-XRF measurements were made of the element concentrations in the unbroken beads obtained, when no melt had remained adhered to the crucible or mould during the preparation process.

Table 4 details the elements analysed, as well as the WD-XRF measurement conditions for each element.

Once the preparation conditions had been established under which reproducible beads were obtained, calibration curves were prepared with each studied bead-releasing agent. In order to verify measurement accuracy, the element concentrations of reference materials prepared under identical conditions were measured by WD-XRF.

Calibrations were prepared for the WD-XRF measurement of two substantially differing types of ceramic materials: clays and zirconium silicates. Different calibrations were prepared for the two types of materials, since the elements to be analysed and their concentration ranges did not coincide.

The concentration ranges of the calibrations, for every analysed element, are shown in Table 5. 
In the calibration process, the values of ' $\alpha$ ' [13] corresponding to the matrix effect of bromine on silicon, iron, calcium, and zirconium were calculated, together with the overlaps of the first-order $\mathrm{K}_{\alpha}$ line of aluminium $(2 \theta=145.12)$ with the first-order $\mathrm{L}_{\alpha}$ line of bromine $(2 \theta=146.66)$, and of the $K_{\alpha}$ line of titanium $(2 \theta=86.14)$ with the $L_{\beta}$ line of iodine $(2 \theta=$ 86.17).

\subsection{Materials and equipment}

The following materials were used as bead-releasing agents: NaI from Panreac (Ref.: 131726), LiBr from Merck (Ref.: 1.05669, Lot: K29338969), $\mathrm{NH}_{4} \mathrm{I}$ from Fluka (Ref.: 09874, Lot: 0100859190), and LiI from Aldrich (Ref.: 223816, Lot: 13503TC).

A 50:50 mixture of lithium metaborate and lithium tetraborate $\left(\mathrm{LiBO}_{2}: \mathrm{Li}_{2} \mathrm{~B}_{4} \mathrm{O}_{7}\right)$ from Alfa Aesar (Ref.: 583001, Lot: 40866) was used as a flux. The flux was controlled using a moisture determination and a blank.

The calibration curves were constructed from mixtures of reference materials. Table 6 lists the reference materials used to prepare the calibration curves for each type of material.

The validation was performed by measuring the following reference materials: GBW 03122 Kaolin, SRM 98b Plastic Clay, and GBW 03103 Shale and Clay for the clay calibration, and BCS-CRM 388 Zircon for the zirconium silicate calibration.

The beads were prepared using a PHILIPS Model PERL X'3 automatic fusion bead machine. Element analysis was performed with a PHILIPS Model PW 2400 XRF wavelength-dispersive X-ray fluorescence spectrometer with Rh target tube and PW 2540 VTC sample changer. 


\section{Results}

\subsection{Results of the effect of each tested release agent}

The experiments performed with the bead-releasing agents and the state of the resulting beads are detailed in Table 7 . The table also shows which tested release agent concentrations were suitable for bead preparation.

Thus, the table shows that $\mathrm{NaI}$ and $\mathrm{LiBr}$ yielded suitable beads for WD-XRF measurement with less than $0.1 \mathrm{~g}$ release agent/bead. In the case of $\mathrm{NH}_{4} \mathrm{I}$, however, a very large quantity (approximately $2 \mathrm{~g} \mathrm{NH}_{4} \mathrm{I} /$ bead) was needed to obtain reproducible beads, while it was also observed that the $\mathrm{NH}_{3}$ emission during fusion had damaged the fusion bead facility.

When LiI was used, a small quantity $(0.11 \mathrm{~g}$ LiI/bead $)$ sufficed to obtain suitable beads for WD-XRF measurement.

\subsection{Results obtained in the validation}

The validation was conducted by preparing beads of reference materials with the different release agents, and measuring the resulting beads in their corresponding calibrations by WDXRF.

The validation results are shown in Tables 8 to 11 . The measurement uncertainty was estimated in accordance with ISO/TAG 4WG3:95 [14, 15]; at least three replicates were analysed per test sample.

When NaI was used as release agent, good results were obtained in the analysis of most major and minor elements, though $\mathrm{Na}$ could not be analysed owing to its presence in the release agent. Furthermore, titanium displayed a greater uncertainty than an identical quantity of any other element as a result of the overlap of the $\mathrm{K}_{\alpha}$ line of titanium with the $\mathrm{L}_{\beta}$ line of the residual iodine in the bead after bead preparation.

The use of $\mathrm{LiBr}$ as release agent required making a series of corrections. First, there was an overlap of the first-order $\mathrm{K}_{\alpha}$ line of aluminium with the first-order $\mathrm{L}_{\alpha}$ line of bromine, which 
led to an error by excess in the measurement of aluminium; however, once this error had been corrected, good results were obtained. Secondly, there was the matrix effect of bromine on zirconium, which was harder to correct, so that the uncertainty obtained in zirconium analysis was high.

It may be noted that, when $\mathrm{NH}_{4} \mathrm{I}$ was used as release agent, better results were obtained in zirconium analysis than when $\mathrm{LiBr}$ was used, since there was no interference on zirconium. The use of $\mathrm{NH}_{4} \mathrm{I}$ entailed a serious drawback, however, in that much of the sulphur present in the clay samples was lost during fusion, making it impossible to analyse sulphur in the beads prepared with $\mathrm{NH}_{4} \mathrm{I}$. In addition, the evolving $\mathrm{NH}_{3}$ emissions in the bead preparation process seriously damaged the fusion bead facility.

Good analytical results were obtained when LiI was used as release agent in the tested ceramic raw materials. There were no problems in the analysis of sulphur or zirconium, though titanium analysis of course required calculation of the overlap with iodide, especially with small titanium concentrations (less than $0.1 \%$ ). Thus, of the bead-releasing agents tested, LiI provided the best results.

\section{Conclusions}

The effect of the use of $\mathrm{NaI}, \mathrm{LiBr}, \mathrm{NH}_{4} \mathrm{I}$, and $\mathrm{LiI}$ as bead-releasing agents in preparing fused bead samples for WD-XRF measurement and their interference with the resulting measurement have been studied. The results allow the following conclusions to be drawn:

- $\mathrm{NaI}$ can be used, incorporated as a solid, in an addition of $0.09 \mathrm{~g} \mathrm{NaI} / \mathrm{bead}$, in beads prepared with a sample:flux ratio of $1: 10$, and sample weight of approximately $0.5 \mathrm{~g}$. However, the use of $\mathrm{NaI}$ is restricted to samples in which sodium is not analysed, since sodium is introduced with the release agent. It addition, the interference of iodine on titanium in the WD-XRF measurement needs to be corrected, especially for low concentrations of titanium, at which the interference is highest. 
- $\mathrm{LiBr}$ provides good analytical results with small additions (0.06 $\mathrm{g} \mathrm{LiBr} / \mathrm{bead})$, but displays a number of limitations. After fusion, a residual quantity of bromine remains in the bead, causing an important overlap with aluminium, in addition to matrix effects on several elements, such as zirconium, silicon, calcium, etc., thus generating considerable measurement uncertainties.

- $\mathrm{NH}_{4} \mathrm{I}$ provides good analytical results for most elements, though it poses a serious problem in sulphur analysis, since sulphur is lost during bead preparation. In addition, the evolving $\mathrm{NH}_{3}$ emission in bead preparation damages the fusion bead facility. Further, just as with NaI, the residual iodine in the bead interferes with titanium and needs to be corrected.

- LiI provides the best results: a relatively small addition $(0.11 \mathrm{LiI} \mathrm{g} / \mathrm{bead})$ yields reproducible beads with no matrix effect on any studied analyte element, while the overlap of iodine with titanium is not significant, since the residual iodine content in the bead is very low.

- The fact that LiI is added in an aqueous solution is a further advantage because the release agent need not be weighed (as is the case when additions are made in solid form), thus making the bead preparation process more rapid and reproducible. The relatively small quantity of LiI required to prepare the beads also makes its use reasonable from a cost-efficiency point of view.

\section{References}

1. Bennett H, Oliver GJ. XRF analysis of ceramics and allied materials. Wiley: Chichester, 1992.

2. Anderson R. Sample pre-treatment and separation. Wiley: Chichester, 1987.

3. Zyl C van. X-Ray Spectrom. 1982; 11: 29-31.

4. Conture RA, Smith MS, Dymek RF. Chem. Geol. 1993; 110: 315-328. 
5. Buhrke E, Jenkins R, Smith DK (eds.). A practical guide for the preparation of specimens for $x$-ray fluorescence and $x$-ray diffraction analysis. Wiley-VCH: New York, 1998.

6. Fusion. In Handbook of sample preparation and handling. Spex CertiPrep: Metuchen, 2000; 68-80.

7. Baker JW. Adv. X. Ray Anal. 1982; 25: 91-94.

8. $\quad$ King BS, Vivit D. X-Ray Spectrom. 1988; 17: 85-87.

9. Bertin EP. Principles and practice of X-Ray spectrometric analysis. Plenum: New York, 1984.

10. Gazulla MF, Gómez MP, Barba A, Jarque JC. X-Ray Spectrom. 2004; 33: 421-430.

11. Gazulla MF, Ochandio E, González T. Téc. Cerám. 1991; 197: 674-678.

12. Gazulla MF, Gómez MP, Barba A, Orduña M Glass Sci. and Technol. 2002; 75: 184-190.

13. Rousseau RM, Bouchard M. X-Ray Spectrom. 1986; 15: 207-215.

14. ISO/TAG 4WG3. 1995. Guide to the expression of uncertainty in measurement.

15. Rashmi UD, Suri DK. X-Ray Spectrom. 1999; 28: 157-162. 
Table 1: Working conditions of the fusion bead machine.

\begin{tabular}{||c|c|c|}
\hline Process stage & Time (min) & Temperature $\left({ }^{\circ} \mathbf{C}\right)$ \\
\hline Oxidisation & 1.30 & 950 \\
\hline 1st Fusion & 1.30 & 1050 \\
\hline 2nd Fusion & 1.30 & 1075 \\
\hline 3rd Fusion & 3.00 & 1100 \\
\hline Pouring & 0.10 & 1100 \\
\hline Solidification and cooling & 1.00 & - \\
\hline
\end{tabular}

Table 2: Tests conducted using $\mathrm{NH}_{4} \mathrm{I}$ as bead-releasing agent.

\begin{tabular}{|c|c|c|c|}
\hline $\begin{array}{l}\text { Form of } \\
\text { addition }\end{array}$ & Concentration $\left(g \cdot \mathbf{L}^{-1}\right)$ & Number of drops & $\mathrm{NH}_{4} \mathrm{I}$ addition (g/bead) \\
\hline \multirow{9}{*}{ Solid } & \multirow{9}{*}{-} & - & 0.10 \\
\hline & & - & 0.20 \\
\hline & & - & 0.30 \\
\hline & & - & 0.40 \\
\hline & & - & 0.60 \\
\hline & & - & 0.80 \\
\hline & & - & 1.00 \\
\hline & & - & 1.50 \\
\hline & & - & 2.00 \\
\hline \multirow{14}{*}{ Solution } & 125 & 42 & 0.26 \\
\hline & 200 & 42 & 0.42 \\
\hline & \multirow{5}{*}{250} & 8 & 0.10 \\
\hline & & 30 & 0.38 \\
\hline & & 60 & 0.75 \\
\hline & & 90 & 1.12 \\
\hline & & 100 & 1.25 \\
\hline & 500 & 50 & 1.25 \\
\hline & 750 & 33 & 1.25 \\
\hline & \multirow{3}{*}{1000} & 12 & 0.60 \\
\hline & & 25 & 1.25 \\
\hline & & 40 & 2.00 \\
\hline & \multirow{2}{*}{1500} & 17 & 1.28 \\
\hline & & 28 & 2.10 \\
\hline
\end{tabular}

Table 3: Tests conducted using LiI as bead-releasing agent.

\begin{tabular}{||c|c|c||}
\hline Concentration $\left(\mathbf{g} \cdot \mathbf{L}^{\mathbf{- 1}}\right)$ & Number of drops & LiI addition $(\mathbf{g} / \mathbf{b e a d})$ \\
\hline \hline \multirow{2}{*}{250} & 4 & 0.05 \\
\cline { 2 - 3 } & 9 & 0.11 \\
\hline
\end{tabular}


Table 4: WD-XRF measurement conditions.

\begin{tabular}{|c|c|c|c|c|c|c|c||}
\hline Element & Line & Crystal & Detector & Voltage (kV) & $\begin{array}{c}\text { Intensity } \\
(\mathbf{m A})\end{array}$ & $\begin{array}{c}\text { Angle } \\
(\mathbf{2 \theta})\end{array}$ & Time (s) \\
\hline \hline $\mathrm{Si}$ & $\mathrm{K} \alpha$ & $\mathrm{InSb} 111-\mathrm{C}$ & Flow & 30 & 90 & 144.3508 & 30 \\
\hline $\mathrm{Al}$ & $\mathrm{K} \alpha$ & $\mathrm{PE} \mathrm{002}$ & Flow & 30 & 90 & 144.9730 & 30 \\
\hline $\mathrm{Fe}$ & $\mathrm{K} \alpha$ & $\mathrm{LiF} 200$ & Flow & 60 & 45 & 57.4992 & 20 \\
\hline $\mathrm{Ca}$ & $\mathrm{K} \alpha$ & $\mathrm{LiF} 200$ & Flow & 45 & 60 & 113.1276 & 10 \\
\hline $\mathrm{Mg}$ & $\mathrm{K} \alpha$ & $\mathrm{PX} 1$ & Flow & 30 & 90 & 22.4820 & 10 \\
\hline $\mathrm{Na}$ & $\mathrm{K} \alpha$ & $\mathrm{PX} 1$ & Flow & 30 & 90 & 27.1592 & 10 \\
\hline $\mathrm{K}$ & $\mathrm{K} \alpha$ & $\mathrm{LiF} 200$ & Flow & 45 & 60 & 136.6762 & 10 \\
\hline $\mathrm{Ti}$ & $\mathrm{K} \alpha$ & $\mathrm{LiF} 200$ & Flow & 45 & 60 & 86.1264 & 10 \\
\hline $\mathrm{Mn}$ & $\mathrm{K} \alpha$ & $\mathrm{LiF} 200$ & Flow & 60 & 45 & 62.9554 & 10 \\
\hline $\mathrm{P}$ & $\mathrm{K} \alpha$ & $\mathrm{Ge} 111$ & Flow & 30 & 90 & 141.0248 & 10 \\
\hline $\mathrm{S}$ & $\mathrm{K} \alpha$ & $\mathrm{Ge} \mathrm{111}$ & Flow & 25 & 90 & 110.6866 & 10 \\
\hline $\mathrm{Zr}$ & $\mathrm{K} \alpha$ & $\mathrm{LiF} 200$ & Scintillation & 45 & 30 & 32.0832 & 10 \\
\hline $\mathrm{Hf}$ & $\mathrm{L} \alpha$ & $\mathrm{LiF} 200$ & Scintillation & 60 & 40 & 45.9226 & 10 \\
\hline $\mathrm{Br}$ & $\mathrm{K} \alpha$ & $\mathrm{LiF} 220$ & Scintillation & 60 & 45 & 42.7706 & 10 \\
\hline $\mathrm{I}$ & $\mathrm{K} \alpha$ & $\mathrm{LiF} 220$ & Scintillation & 60 & 40 & 17.4300 & 10 \\
\hline
\end{tabular}

Table 5: Concentration ranges used for each element (expressed as oxide wt\%) in the calibrations made for the studied clays and zirconium silicates.

\begin{tabular}{|c|c|c|}
\cline { 2 - 3 } \multicolumn{1}{c|}{} & Clays & Zirconium silicates \\
\hline \hline Constituent & Concentration ranges (wt\%) & Concentration ranges (wt\%) \\
\hline $\mathrm{SiO}_{2}$ & $30-75$ & $32-45$ \\
\hline $\mathrm{Al}_{2} \mathrm{O}_{3}$ & $10-35$ & $0-3$ \\
\hline $\mathrm{Fe}_{2} \mathrm{O}_{3}$ & $0-12$ & $0-0.5$ \\
\hline $\mathrm{CaO}$ & $0-9$ & $0-0.5$ \\
\hline $\mathrm{MgO}$ & $0-7$ & $0-0.5$ \\
\hline $\mathrm{Na}_{2} \mathrm{O}$ & $0-9$ & $0-0.3$ \\
\hline $\mathrm{K}_{2} \mathrm{O}$ & $0-7$ & $0-0.2$ \\
\hline $\mathrm{TiO}_{2}$ & $0-2$ & $0-0.5$ \\
\hline $\mathrm{MnO}_{\mathrm{P} O} \mathrm{O}_{5}$ & $0-0.2$ & - \\
\hline $\mathrm{ZrO}_{2}$ & $0-1$ & $0-0.3$ \\
\hline $\mathrm{HfO}_{2}$ & - & $50-65$ \\
\hline $\mathrm{S}$ & - & $0-2$ \\
\hline & $0-0.1$ & - \\
\hline
\end{tabular}

Table 6: Reference materials used to construct the calibration curves.

\begin{tabular}{|c|c|}
\hline Clays & Zirconium silicates \\
\hline BCS-CRM 348 Ball Clay & SARM 13 (Zircon Concentrate) \\
CAS 5 Ball Clay & BCS-CRM 313/1 High Purity Silica \\
GBW 03118 Graphite Ore & BCS-CRM 358 Zirconia \\
GBW 03102 Clay & BCS 394 Calcined Bauxite \\
GBW 07404 Soil & \\
\hline
\end{tabular}


Table 7: Results of the tested bead-releasing agents.

\begin{tabular}{|c|c|c|c|c|}
\hline Release agent & $\begin{array}{l}\text { Form of } \\
\text { addition }\end{array}$ & $\begin{array}{l}\text { Concentration in the } \\
\text { bead (g/bead) }\end{array}$ & $\begin{array}{c}\text { State of the resulting bead } \\
\text { and crucible }\end{array}$ & Result \\
\hline $\mathrm{NaI}$ & Solid & 0.09 & Good bead and clean crucible & Suitable \\
\hline $\mathrm{LiBr}$ & Solution & 0.06 & Good bead and clean crucible & Suitable \\
\hline \multirow{20}{*}{$\mathrm{NH}_{4} \mathrm{I}$} & \multirow{9}{*}{ Solid } & 0.10 & \multirow{4}{*}{$\begin{array}{l}\text { Broken bead and melt adhered to the } \\
\text { crucible }\end{array}$} & \multirow{4}{*}{ Unsuitable } \\
\hline & & 0.20 & & \\
\hline & & 0.30 & & \\
\hline & & 0.40 & & \\
\hline & & 0.60 & \multirow{5}{*}{$\begin{array}{l}\text { Unbroken bead and melt adhered to } \\
\text { the crucible }\end{array}$} & \multirow{5}{*}{ Unsuitable } \\
\hline & & 0.80 & & \\
\hline & & 1.00 & & \\
\hline & & 1.50 & & \\
\hline & & 2.00 & & \\
\hline & \multirow{11}{*}{ Solution } & 0.26 & \multirow{4}{*}{$\begin{array}{l}\text { Broken bead and melt adhered to the } \\
\text { crucible }\end{array}$} & \multirow{4}{*}{ Unsuitable } \\
\hline & & 0.42 & & \\
\hline & & 0.10 & & \\
\hline & & 0.38 & & \\
\hline & & 0.75 & \multirow{2}{*}{$\begin{array}{l}\text { Unbroken bead and melt adhered to } \\
\text { the crucible }\end{array}$} & \multirow{2}{*}{ Unsuitable } \\
\hline & & 1.12 & & \\
\hline & & 1.25 & Good bead and clean crucible & Suitable \\
\hline & & 0.60 & $\begin{array}{l}\text { Unbroken bead and melt adhered to } \\
\text { the crucible }\end{array}$ & Unsuitable \\
\hline & & 2.00 & Good bead and clean crucible & Suitable \\
\hline & & 1.28 & $\begin{array}{l}\text { Unbroken bead and slight amount of } \\
\text { melt adhered to the crucible }\end{array}$ & Unsuitable \\
\hline & & 2.10 & Good bead and clean crucible & Suitable \\
\hline \multirow[t]{2}{*}{ LiI } & \multirow[t]{2}{*}{ Solution } & 0.05 & $\begin{array}{l}\text { Unbroken bead and melt adhered to } \\
\text { the crucible }\end{array}$ & Unsuitable \\
\hline & & 0.11 & Good bead and clean crucible & Suitable \\
\hline
\end{tabular}

Table 8: Results of the WD-XRF measurements of beads made, respectively, with SRM 98b Plastic Clay, GBW 03122 Kaolin, and BCS-CRM 388 Zircon, using NaI as release agent.

\begin{tabular}{|c|c|c|c|c|c|c||}
\hline \multirow{3}{*}{ Constituent } & \multicolumn{3}{|c|}{ Certified value (wt\%) } & \multicolumn{3}{c||}{ Experimental value (wt\%) } \\
\cline { 2 - 7 } & SRM 98b & GBW 03122 & $\begin{array}{c}\text { BCS-CRM } \\
\mathbf{3 8 8}\end{array}$ & SRM 98b & GBW 03122 & $\begin{array}{c}\text { BCS-CRM } \\
\text { 388 }\end{array}$ \\
\hline $\mathrm{SiO}_{2}$ & 57.00 & 44.53 & 32.7 & $57.1 \pm 0.4$ & $44.5 \pm 0.4$ & $32.6 \pm 0.5$ \\
\hline $\mathrm{Al}_{2} \mathrm{O}_{3}$ & 27.01 & 38.62 & 0.291 & $26.9 \pm 0.2$ & $38.6 \pm 0.2$ & $0.3 \pm 0.1$ \\
\hline $\mathrm{Fe}_{2} \mathrm{O}_{3}$ & 1.69 & 0.72 & 0.049 & $1.69 \pm 0.02$ & $0.71 \pm 0.02$ & $0.05 \pm 0.01$ \\
\hline $\mathrm{CaO}$ & 0.110 & 0.16 & 0.035 & $0.11 \pm 0.01$ & $0.16 \pm 0.01$ & $0.03 \pm 0.01$ \\
\hline $\mathrm{MgO}$ & 0.590 & 0.068 & 0.03 & $0.58 \pm 0.03$ & $0.07 \pm 0.01$ & $0.03 \pm 0.01$ \\
\hline $\mathrm{Na}_{2} \mathrm{O}$ & 0.202 & 0.069 & 0.016 & - & - & - \\
\hline $\mathrm{K}_{2} \mathrm{O}$ & 3.39 & 0.049 & 0.017 & $3.40 \pm 0.04$ & $0.05 \pm 0.01$ & $0.02 \pm 0.01$ \\
\hline $\mathrm{TiO}_{2}$ & 1.349 & 0.39 & 0.232 & $1.28 \pm 0.10$ & $0.41 \pm 0.05$ & $0.24 \pm 0.05$ \\
\hline $\mathrm{MnO}^{\mathrm{P}} \mathrm{O}_{5}$ & 0.015 & 0.0054 & - & $0.01 \pm 0.01$ & $0.01 \pm 0.01$ & - \\
\hline $\mathrm{ZrO}_{2}$ & 0.070 & 0.21 & 0.12 & $0.07 \pm 0.01$ & $0.20 \pm 0.02$ & $0.12 \pm 0.02$ \\
\hline $\mathrm{HfO}_{2}$ & - & - & 64.9 & - & - & $64.8 \pm 0.2$ \\
\hline
\end{tabular}


Table 9: Results of the WD-XRF measurements of beads made, respectively, with GBW 03103 Shale and Clay, GBW 03122 Kaolin, and BCS-CRM 388 Zircon, using LiBr as bead-releasing agent.

\begin{tabular}{|c|c|c|c|c|c|c||}
\hline \multirow{2}{*}{ Constituent } & \multicolumn{3}{|c|}{ Certified value (wt\%) } & \multicolumn{3}{c||}{ Experimental value (wt\%) } \\
\cline { 2 - 7 } & GBW 03103 & GBW 03122 & $\begin{array}{c}\text { BCS-CRM } \\
\mathbf{3 8 8}\end{array}$ & GBW 03103 & GBW 03122 & $\begin{array}{c}\text { BCS-CRM } \\
\mathbf{3 8 8}\end{array}$ \\
\hline $\mathrm{SiO}_{2}$ & 66.64 & 44.53 & 32.7 & $66.5 \pm 0.4$ & $44.5 \pm 0.3$ & $32.8 \pm 0.4$ \\
\hline $\mathrm{Al}_{2} \mathrm{O}_{3}$ & 13.28 & 38.62 & 0.291 & $13.2 \pm 0.2$ & $38.5 \pm 0.2$ & $0.30 \pm 0.05$ \\
\hline $\mathrm{Fe}_{2} \mathrm{O}_{3}$ & 4.64 & 0.72 & 0.049 & $4.65 \pm 0.02$ & $0.71 \pm 0.02$ & $0.05 \pm 0.01$ \\
\hline $\mathrm{CaO}$ & 3.23 & 0.16 & 0.035 & $3.21 \pm 0.08$ & $0.16 \pm 0.01$ & $0.04 \pm 0.01$ \\
\hline $\mathrm{MgO}$ & 1.84 & 0.068 & 0.03 & $1.84 \pm 0.05$ & $0.07 \pm 0.01$ & $0.03 \pm 0.01$ \\
\hline $\mathrm{Na}_{2} \mathrm{O}$ & 1.81 & 0.069 & 0.016 & $1.80 \pm 0.05$ & $0.07 \pm 0.01$ & $0.02 \pm 0.01$ \\
\hline $\mathrm{K}_{2} \mathrm{O}$ & 2.50 & 0.049 & 0.017 & $2.48 \pm 0.08$ & $0.05 \pm 0.01$ & $0.02 \pm 0.01$ \\
\hline $\mathrm{TiO}_{2}$ & 0.66 & 0.39 & 0.232 & $0.66 \pm 0.05$ & $0.38 \pm 0.04$ & $0.23 \pm 0.04$ \\
\hline $\mathrm{MnO}$ & 0.088 & 0.0054 & - & $0.09 \pm 0.01$ & $<0.01 \pm 0.01$ & - \\
\hline $\mathrm{P}_{2} \mathrm{O}_{5}$ & 0.106 & 0.21 & 0.12 & $0.10 \pm 0.01$ & $0.21 \pm 0.09$ & $0.12 \pm 0.02$ \\
\hline $\mathrm{ZrO}_{2}$ & - & - & 64.9 & - & - & $64.7 \pm 0.5$ \\
\hline $\mathrm{HfO}_{2}$ & - & - & 1.3 & - & - & $1.24 \pm 0.10$ \\
\hline $\mathrm{S}$ & 0.0108 & 0.048 & - & $0.011 \pm 0.003$ & $0.048 \pm 0.004$ & - \\
\hline
\end{tabular}

Table 10: Results of the WD-XRF measurements of beads made, respectively, with GBW 03103 Shale and Clay, and BCS-CRM 388 Zircon, using $\mathrm{NH}_{4} \mathrm{I}$ as bead-releasing agent.

\begin{tabular}{|c|c|c|c|c||}
\hline \multirow{2}{*}{ Constituent } & \multicolumn{2}{|c|}{ Certified value (wt\%) } & \multicolumn{2}{c||}{ Experimental value (wt\%) } \\
\cline { 2 - 5 } & BCS-CRM 388 & GBW 03103 & BCS-CRM 388 & GBW 03103 \\
\hline $\mathrm{SiO}_{2}$ & 32.7 & 66.64 & $32.7 \pm 0.4$ & $66.7 \pm 0.4$ \\
\hline $\mathrm{Al}_{2} \mathrm{O}_{3}$ & 0.291 & 13.28 & $0.3 \pm 0.1$ & $13.3 \pm 0.2$ \\
\hline $\mathrm{Fe}_{2} \mathrm{O}_{3}$ & 0.049 & 4.64 & $0.05 \pm 0.01$ & $4.68 \pm 0.08$ \\
\hline $\mathrm{CaO}$ & 0.035 & 3.23 & $0.04 \pm 0.01$ & $3.20 \pm 0.05$ \\
\hline $\mathrm{MgO}$ & 0.03 & 1.84 & $0.03 \pm 0.01$ & $1.86 \pm 0.03$ \\
\hline $\mathrm{Na}_{2} \mathrm{O}$ & 0.016 & 1.81 & $0.02 \pm 0.01$ & $1.82 \pm 0.03$ \\
\hline $\mathrm{K}_{2} \mathrm{O}$ & 0.017 & 2.50 & $0.02 \pm 0.01$ & $2.51 \pm 0.04$ \\
\hline $\mathrm{TiO}_{2}$ & 0.232 & 0.66 & $0.23 \pm 0.02$ & $0.66 \pm 0.02$ \\
\hline $\mathrm{MnO}^{\mathrm{P} O} \mathrm{O}_{5}$ & - & 0.088 & - & $0.09 \pm 0.01$ \\
\hline $\mathrm{ZrO}_{2}$ & 0.12 & 0.106 & $0.12 \pm 0.02$ & $0.11 \pm 0.01$ \\
\hline $\mathrm{HfO}_{2}$ & 64.9 & - & $65.0 \pm 0.1$ & - \\
\hline $\mathrm{S}$ & 1.3 & - & $1.35 \pm 0.08$ & - \\
\hline
\end{tabular}

Table 11 Results of the WD-XRF measurements of beads made, respectively, with GBW 03103 Shale and Clay, and BCS-CRM 388 Zircon, using LiI as bead-releasing agent.

\begin{tabular}{|c|c|c|c|c||}
\hline \multirow{2}{*}{ Constituent } & \multicolumn{2}{|c|}{ Certified value (wt\%) } & \multicolumn{2}{c||}{ Experimental value (wt\%) } \\
\cline { 2 - 5 } & BCS-CRM 388 & GBW 03103 & BCS-CRM 388 & GBW 03103 \\
\hline $\mathrm{SiO}_{2}$ & 32.7 & 66.64 & $32.5 \pm 0.4$ & $66.7 \pm 0.4$ \\
\hline $\mathrm{Al}_{2} \mathrm{O}_{3}$ & 0.291 & 13.28 & $0.3 \pm 0.1$ & $13.2 \pm 0.2$ \\
\hline $\mathrm{Fe}_{2} \mathrm{O}_{3}$ & 0.049 & 4.64 & $0.05 \pm 0.01$ & $4.62 \pm 0.05$ \\
\hline $\mathrm{CaO}$ & 0.035 & 3.23 & $0.04 \pm 0.01$ & $3.25 \pm 0.05$ \\
\hline $\mathrm{MgO}$ & 0.03 & 1.84 & $0.03 \pm 0.01$ & $1.84 \pm 0.03$ \\
\hline $\mathrm{Na}_{2} \mathrm{O}$ & 0.016 & 1.81 & $0.02 \pm 0.01$ & $1.82 \pm 0.02$ \\
\hline $\mathrm{K}_{2} \mathrm{O}$ & 0.017 & 2.50 & $0.02 \pm 0.01$ & $2.52 \pm 0.05$ \\
\hline $\mathrm{TiO}_{2}$ & 0.232 & 0.66 & $0.21 \pm 0.04$ & $0.69 \pm 0.04$ \\
\hline $\mathrm{MnO}^{\mathrm{P} O} \mathrm{O}_{5}$ & - & 0.088 & - & $0.09 \pm 0.01$ \\
\hline $\mathrm{ZrO}_{2}$ & 0.12 & 0.106 & $0.11 \pm 0.02$ & $0.11 \pm 0.02$ \\
\hline $\mathrm{HfO}_{2}$ & 64.9 & - & $64.9 \pm 0.1$ & - \\
\hline $\mathrm{S}$ & 1.3 & - & $1.32 \pm 0.06$ & - \\
\hline
\end{tabular}

